Virginia Commonwealth University VCU Scholars Compass

2017

\title{
Assessing efficiency of public health and medical care provision in OECD countries after a decade of reform
}

\author{
Yasar A. Ozcan \\ Virginia Commonwealth University, ozcan@vcu.edu \\ Jaya Khushalani \\ Virginia Commonwealth University
}

Follow this and additional works at: http://scholarscompass.vcu.edu/hadm_pubs

Part of the Health and Medical Administration Commons

(C) Springer-Verlag Berlin Heidelberg 2016

\section{Downloaded from}

http://scholarscompass.vcu.edu/hadm_pubs/11 


\title{
Assessing efficiency of public health and medical care provision in OECD countries after a decade of reform
}

\author{
$\operatorname{Yasar}_{A}$ Ozcan $^{1}$ (D) Jaya Khushalani ${ }^{1}$
}

Published online: 8 March 2016

(C) Springer-Verlag Berlin Heidelberg 2016

\begin{abstract}
The objective of this study was to examine the change in efficiency of health care systems of 34 OECD countries between 2000 and 2012, a period marked by significant health reform in most OECD countries. This paper uses a novel Dynamic Network Data Envelopment Analysis (DNDEA) model to analyze the efficiency of the public health system and the medical care system of these OECD countries independently along with assessing the efficiency of their overall health system. This helps understand the relative priorities for improving the overall health system. The data for this study was obtained from the OECD Health Facts database. The study findings suggest that countries which improved their public health system were more likely to show overall improvement in efficiency.
\end{abstract}

Keywords Efficiency $\cdot$ OECD $\cdot$ DNDEA $\cdot$ Public health $\cdot$ Health reform

\section{Introduction}

Health care systems in Organization for Economic Cooperation and Development (OECD) countries are continuously striving to adapt to economic, social and political demands. Change in demographics, political climates and disease trends in the last decade have forced OECD countries to make a number of changes in their health care system. OECD countries face similar challenges as the demand for quality health care

Yasar A. Ozcan

ozcan@vcu.edu

Jaya Khushalani

khushalanijs@vcu.edu

1 Department of Health Administration, Virginia Commonwealth University, 1008 East Clay Street, PO Box 980203, Richmond, VA 23298-0203, USA 
surpasses the resources of public health and medical care divisions of these countries. Global health challenges which include an aging population, lack of balance between containing costs while maintaining access and quality, shift from acute to chronic diseases which lead to a higher burden on medical care resources and fragmented health care systems have prompted OECD countries to make major changes to their health care system in the last decade (Yaya and Danhoundo 2015). These changes vary from policy changes within a particular sector to a sweeping health care reform spanning multiple sectors. A number of OECD countries such as Austria (Nolte et al. 2012), Canada (Simms 2010), Chile (Unger et al. 2008), Denmark (Andersen and Jensen 2010; Magnussen et al. 2009), Estonia (Thomson et al. 2010), Germany (Gerlinger 2010; Nolte et al. 2012), Japan (Ikegami and Campbell 2004), Mexico (Laurell 2007), Netherlands (Nolte et al. 2012; Schafer et al. 2010), Norway (Byrkjeflot 2004; Magnussen et al. 2009), Portugal (Barros 2012), Slovakia (Szalay et al. 2011) and Turkey (Aktan et al. 2014; Kacak et al. 2014; Narc1 et al. 2015) and United States (Gruber and Sekhon 2010) undertook significant healthcare reforms over the last decade. OECD countries like Australia (National Health and Hospitals Reform Commission 2009), Czech Republic (Office of the Government of the Czech Republic 2013), Finland (Magnussen et al. 2009), Greece (Boutsioli 2011), Hungary (Gaal 2011) and Ireland (Tussing and Wren 2006) are currently at various stages of planning and implementing health system reform.

OECD countries have different models of health care financing and delivery. Thus, each country has its own unique set of issues that are addressed by reforms. In spite of this diversity, health reforms in most OECD countries have a number of common features. These include expanding focus on primary care and community-based care, enhancing health care access to the disadvantaged and vulnerable, engaging consumers in their care, changing payment and reimbursement models to obtain better quality, robust quality measurement, integration between various sectors of the medical care division and between public health and medical care and lastly, moving towards increased use of health information technology (Yaya and Danhoundo 2015). Table 1 provides a short description of the nature of reforms undertaken by some OECD countries between 2000 and 2012. We restrict to reforms during this period since this is the period of data we analyze in this paper.

As can be seen from Table 1, the most important common feature of all these reforms is cost-containment and deriving better value for the resources spent. Efficiency is thus an important component of health care reform.

A number of studies have attempted to examine the efficiency of health care systems of OECD countries. Most of these studies used Data Envelopment Analysis (DEA) to derive efficiency scores for OECD countries' health systems along with comparative rankings for the countries compared (Afonso and St Aubyn 2006; Häkkinen and Joumard 2007; Hollingsworth and Wildman 2003; Mohan and Mirmirani 2007; Retzlaff-Roberts et al. 2004). Traditional DEA models treat a health care system as a black box while computing efficiency based on a set of inputs and outputs. This makes it difficult to differentiate the efficiency of various components of a health system. According to the expert panel on Understanding Cross-National Health Differences among High-Income Countries, a health system encompasses the full continuum between public health (population-based services) and medical care (delivered 
Table 1 Health reform in OECD countries between 2000 and 2012

\begin{tabular}{|c|c|c|}
\hline Country & Description of reform & $\begin{array}{l}\text { Year in which reform } \\
\text { was implemented }\end{array}$ \\
\hline Austria & $\begin{array}{l}\text { To change reimbursement mechanisms in order to } \\
\text { promote cost containment and care coordination }\end{array}$ & 2005 \\
\hline Canada & $\begin{array}{l}\text { To change the primary care system including delivery } \\
\text { system integration in order to promote cost } \\
\text { containment and care coordination }\end{array}$ & Since 2000 \\
\hline Chile & $\begin{array}{l}\text { To increase access to health care for patients with } \\
\text { chronic diseases }\end{array}$ & 2005 \\
\hline Denmark & $\begin{array}{l}\text { To centralize and modernize the hospital sector; } \\
\text { increase role of municipalities in providing health } \\
\text { care; improve coordination across different levels of } \\
\text { the public sector and policy areas }\end{array}$ & 2007 \\
\hline Estonia & $\begin{array}{l}\text { To improve hospital and long term care infrastructure } \\
\text { and quality }\end{array}$ & 2000 \\
\hline Germany & $\begin{array}{l}\text { To increased cost sharing for beneficiaries of social } \\
\text { health insurance and to promote care coordination }\end{array}$ & 2004 \\
\hline Japan & $\begin{array}{l}\text { Patchwork reform undertaken over a period of time to } \\
\text { promote care coordination, quality care in hospitals } \\
\text { and cost containment }\end{array}$ & NA \\
\hline Mexico & To expand insurance coverage to the underserved & 2001 \\
\hline Netherlands & $\begin{array}{l}\text { To introduce managed competition among insurers and } \\
\text { providers in order to promote cost containment }\end{array}$ & 2006 \\
\hline Norway & $\begin{array}{l}\text { Multiple reforms to improve primary care and hospital } \\
\text { care in order to promote care coordination and cost } \\
\text { containment }\end{array}$ & 2001, 2002 and 2009 \\
\hline Portugal & $\begin{array}{l}\text { To reform primary care in order to promote care } \\
\text { coordination and cost containment }\end{array}$ & 2005 \\
\hline Slovakia & $\begin{array}{l}\text { To ensure compulsory social health insurance and to } \\
\text { decentralize hospitals }\end{array}$ & 2005 \\
\hline Turkey & $\begin{array}{l}\text { To organize and expand of health insurance coverage to } \\
\text { the underserved; to reorganize payment mechanisms; } \\
\text { to provide incentives for quality through pay for } \\
\text { performance; to ensure more autonomy and flexibility } \\
\text { for hospitals; to provide health services through } \\
\text { public-private partnerships; and to improve family } \\
\text { medicine }\end{array}$ & 2003 \\
\hline United States & $\begin{array}{l}\text { To expand health insurance coverage to the underserved; } \\
\text { to change delivery and reimbursement models to } \\
\text { promote care coordination and cost containment }\end{array}$ & 2010 \\
\hline
\end{tabular}

to individual patients). The panel recommends that both these components-public health and medical care-must be examined while making cross-national comparisons (Woolf and Aron 2013).

The importance of population-based services is marked by the signature accomplishments of public health, such as the control of vaccine-preventable diseases, lead abatement, tobacco control, motor vehicleo ccupant restraints, and water fluoridation 
to prevent dental caries (Centers for Disease Control and Prevention 1999). Public health efforts are credited with much of the gains in life expectancy that high-income countries experienced in the twentieth century (Cutler and Miller 2005; Foege 2004). The importance of medical care is marked by the fact that $50 \%$ of US deaths that would otherwise have occurred are averted by medical care (Woolf and Aron 2013). Thus, both public health and medical care are equally important components of a health system.

Essential services to be provided by public health in any health system include monitoring health status to identify community health problems, diagnosing and investigate health problems in the community, educating people about health issues, developing policies that support community health efforts, enforce laws and regulations that protect health and ensure safety and lastly linking people who cannot otherwise access health care to necessary health care services (Fielding et al. 2008). OECD countries differ on how fragmented their public health system is i.e. whether public health is provided based on a comprehensive national policy (e.g. Denmark, Finland, Sweden) or whether public health delivery is provided by state and local departments in a fragmented manner (United States, Australia, Netherlands, etc.) (Allin et al. 2004). These countries also differ on the amount of health care expenditure dedicated to public health. Lastly, the public health systems in OECD countries differ on the provision of the last essential service i.e. providing a safety net for individuals who do not have any other means to access health care. This can be measured by an index called "Health care decommodification" which refers to the extent to which individuals' access to health care is independent of their financial resources or the market. British social scientist Clare Bambra developed the health care decommodification index and found that the United States had the lowest decommodification score (9.0) followed by Australia (20.0) among 14 peer countries whereas UK and Norway had the highest decommodification score (60.0) (Bambra and Beckfield 2011). There exists interplay between public health and medical care. The successes of public health system which include immunizations and preventive services like screenings reduce the burden on the medical care system and issues identified by the medical care system become priorities for the public health system.

Based on who provides and who pays for medical care, medical care systems in OECD countries can be categorized into four models: (a) the Beveridge Model or the single payer national health service model where health care is provided and financed by the government through tax payments (examples-Australia, Chile, Denmark, Finland, Greece, Iceland, Ireland, Italy, Korea, Mexico, Norway, New Zealand, Poland, Portugal, Spain, Sweden, Turkey, UK); (b) the Bismarck Model or the social insurance model which uses an insurance system called "sickness funds" which is usually financed jointly by employers and employees through payroll deduction. Although this is a multi-payer model tight regulation gives government much of the cost-control clout that the single-payer Beveridge Model provides.Provision of medical care in this model is by the private sector. (examples-Austria, Belgium, Czech Republic, Estonia, France, Germany, Hungary, Israel, Japan, Luxemborg, Netherlands, Slovak Republic, Slovenia, Switzerland); (c) the National Health Insurance Model or the single payer national health insurance model where the single-payer is a government run insurance that every citizen has to contribute to. Medical care is provided by the private sector. 
(examples- Canada) and (d) out of pocket modelwhere individuals pay for medical care provided by the private sector using out of pocket funds or private sector insurancepurchased by people with no government oversight (example-United States) (Reid 2010; Kulesher and Forrestal 2014). Thus, sufficient differences exist between OECD countries in the organization of their public health and medical care system. However, traditional black-box DEA models do not allow comparison of these two divisions of the health system independently.

Traditional black-box DEA models are unable to examine the efficiency of the public health and medical care divisions independently or the impact of public health on medical care and overall health system. Such an analysis is essential in order to understand the specific factors which contribute to inefficiencies in OECD countries. Network DEA models go beyond the traditional black box model and allow computation of divisional efficiencies in addition to the efficiency for the entire health system (Tone and Tsutsui 2009). This paper is one of the first attempts at a cross-national comparison of efficiency of public health and medical care divisions of health systems in OECD countries before and after a decade of reform.

\subsection{Dynamic Network DEA (DNDEA)}

Network DEA models were first introduced by Färe and Grosskopf (2000) and have been extended by Tone and Tsutsui (2009). However, the Network DEA model can only be used to compute efficiency for a single time period. The Dynamic Network DEA (DNDEA) model extends the Network DEA model by computing absolute efficiency scores and changes in divisional and health system efficiencies over multiple time periods. It can compute overall efficiency scores for public health division, medical care division and the overall health system over all time periods based on long-term optimization using carry-over variables which are essentially links from one time period to the other. Traditionally, efficiency change over time was computed using Windows analysis by Klopp (1985) and the Malmquist index developed by Färe et al. (1994). The DNDEA model is similar to the Malmquist index model and breaks down the overall change in efficiency into two components: Frontier change (change in efficiency across all health systems in the peer group due to change in innovation) and Catch-up (distance of the focus health system from the efficiency frontier). Although the Malmquist index has been used for a number of applications in healthcare, the DNDEA is a relatively new model. The only published application of DNDEA model in health care was by Kawaguchi et al. (2014) in their evaluation of the efficiency of Japanese municipal hospitals in response to policy reform. DNDEA models provide significant advantage in separately evaluating impact of reform on public health and medical care divisions of a health system.

\subsection{Formulae for efficiency in Dynamic Network DEA}

We deal with $n$ DMUs $(j=1, \ldots, n)$ consisting of $K$ divisions $(k=1, \ldots, K)$ over $T$ time periods $(t=1, \ldots, T)$. Let $m_{k}$ and $r_{k}$ be the numbers of inputs and outputs of 
Division $k$, respectively. We denote the link leading from Division $k$ to Division $h$ by $(k, h)$ and the set of links by $L$. The observed data are as follows:

$\left\{x_{i j k}^{t} \in R_{+}\right\}\left(i=1, \ldots, m_{k} ; j=1, \ldots, n ; k=1, \ldots, K ; t=1, \ldots, T\right)$ (input resource $i$ to $\mathrm{DMU}_{j}$ for Division $k$ in period $t$ ),

$\left\{y_{i j k}^{t} \in R_{+}\right\}\left(i=1, \ldots, r_{k} ; j=1, \ldots, n ; k=1, \ldots, K ; t=1, \ldots, T\right)$ (output product $i$ from $\mathrm{DMU}_{j}$, Division $k$, in period $t$ ). If some outputs are undesirable, we treat them as inputs to Division $k$.

$\left\{z_{j(k h)_{l}}^{t} \in R_{+}\right\}\left(j=1, \ldots, n ; l=1, \ldots, L_{k h} ; t=1, \ldots, T\right)$ (linking intermediate products of DMU $j$ from Division $k$ to Division $h$ in period $t$, where $L_{k h}$ is the number of items in links from $k$ to $h).\left\{z_{j k_{l}}^{(t, t+1)} \in R_{+}\right\}(j=1, \ldots, n ; l=$ $1, \ldots, L_{k} ; k=1, \ldots, K ; t=1, \ldots, T-1$ ) (carry-over of DMU $j$, Division $k$, from period $t$ to period $t+1$, where $L_{k}$ is the number of items in the carry-over from Division $k$.)

\subsection{Expression for $\mathrm{DMU}_{o}$}

$\operatorname{DMU}_{o}(o=1, \ldots, n) \in P$ can be expressed as follows.

$$
\begin{aligned}
\mathbf{x}_{o k}^{t} & =\mathbf{X}_{k}^{t} \lambda_{k}^{t}+\mathbf{s}_{k o}^{t-} \quad(k=1, \ldots, K ; t=1, \ldots, T) \\
\mathbf{y}_{o k}^{t} & =\mathbf{Y}_{k}^{t} \lambda_{k}^{t}-\mathbf{s}_{k o}^{t+} \quad(k=1, \ldots, K ; t=1, \ldots, T) \\
\mathbf{e} \lambda_{k}^{t} & =1 \quad(k=1, \ldots, K ; t=1, \ldots, T) \\
\lambda_{k}^{t} & \geq \mathbf{0}, \quad \mathbf{s}_{k o}^{t-} \geq \mathbf{0}, \mathbf{s}_{k o}^{t+} \geq \mathbf{0}, \quad(\forall k, \forall t)
\end{aligned}
$$

Where $\mathbf{X}_{k}^{t}=\left(\mathbf{x}_{1 k}^{t}, \ldots, \mathbf{x}_{n k}^{t}\right) \in R^{m_{k} \times n \times T}$ and $\mathbf{Y}_{k}^{t}=\left(\mathbf{y}_{1 k}^{t}, \ldots, \mathbf{y}_{n k}^{t}\right) \in R^{r_{k} \times n \times T}$ are input and output matrices, and $\mathbf{s}_{k o}^{t-}$ and $\mathbf{s}_{k o}^{t+}$ are input/output slacks, respectively.

As regard to the linking constraints, there are several options as follows:

The "as input" link value case (LB): The linking activities are treated as input to the succeeding division and excesses are accounted for in the input inefficiency.

$$
\mathbf{z}_{o(k h) i n}^{t}=\mathbf{Z}_{(k h) i n}^{t} \lambda_{k}^{t}+\mathbf{s}_{o(k h) i n}^{t} \quad\left((k h) i n=1, \ldots, \operatorname{linkin}_{k}\right)
$$

where $\mathbf{s}_{o(k h) i n}^{t} \in R^{L_{(k h) i n}}$ is slacks and non-negative, and $l i n k i n_{k}$ is the number of "as input" link from division $k$.

The "as output" link value case (LG): The linking activities are treated as output from the preceding division and shortages are accounted for in the output inefficiency.

$$
\mathbf{z}_{o(k h) \text { out }}^{t}=\mathbf{Z}_{(k h) \text { out }}^{t} \lambda_{k}^{t}-\mathbf{s}_{o(k h) \text { out }}^{t} \quad\left((k h) \text { out }=1, \ldots, \text { linkout }_{k}\right)
$$

where $\mathbf{s}_{o(k h) \text { out }}^{t} \in R^{L_{(k h) o u t}}$ is slacks and non-negative and linkout $t_{k}$ is the number of "as output" links from Division $k$.

Carry-over activities can be classified into four categories as follows. Corresponding to each category of carry-over, we derive the following equations: 


$$
\begin{aligned}
& z_{\text {oklgood }}^{(t, t+1)}=\sum_{j=1}^{n} z_{j k_{l} \text { good }}^{(t, t+1)} \lambda_{j k}^{t}-s_{\text {okl good }}^{(t, t+1)} \\
& \left(k_{l}=1, \ldots, \operatorname{ngood}_{k} ; k=1, \ldots, K ; t=1, \ldots, T\right) \\
& z_{\text {okl bad }}^{(t, t+1)}=\sum_{j=1}^{n} z_{j k_{l} \text { bad }}^{(t, t+1)} \lambda_{j k}^{t}+s_{o k_{l} \text { bad }}^{(t, t+1)} \\
& \left(k_{l}=1, \ldots, \operatorname{nbad}_{k} ; k=1, \ldots, K ; \quad t=1, \ldots, T\right) \\
& z_{\text {okl free }}^{(t, t+1)}=\sum_{j=1}^{n} z_{j k_{l} \text { free }}^{(t, t+1)} \lambda_{j k}^{t}+s_{o k_{l} \text { free }}^{(t, t+1)} \\
& \left(k_{l}=1, \ldots, n f r e e_{k} ; k=1, \ldots, K ; t=1, \ldots, T\right) \\
& z_{o k_{l} f i x}^{(t, t+1)}=\sum_{j=1}^{n} z_{j k_{l} f i x}^{(t, t+1)} \lambda_{j k}^{t} \quad\left(k_{l}=1, \ldots, n f i x_{k} ; k=1, \ldots, K ; t=1, \ldots, T\right) \\
& s_{\text {oklgood }}^{(t, t+1)} \geq 0, s_{o k_{l} \text { bad }}^{(t, t+1)} \geq 0 \text { and } s_{o k_{l} \text { free }}^{(t, t+1)} \text { :free }\left(\forall k_{l} ; \forall t\right)
\end{aligned}
$$

where $s_{o k_{l} \text { good }}^{(t, t+1)}, s_{o k_{l} \text { bad }}^{(t, t+1)}$ and $s_{o k_{l} \text { free }}^{(t, t+1)}$ are slacks denoting, respectively, carry-over shortfall, carry-over excess and carry-over deviation, and $n \operatorname{good}_{k}, \operatorname{nbad}_{k}$ and $n \mathrm{free}_{k}$ indicate, respectively, the number of desirable (good), undesirable (bad) and free carryovers for each division $k$.

\subsection{Objective function for overall-, period- and divisional efficiency}

The overall-efficiency is evaluated by the following program:

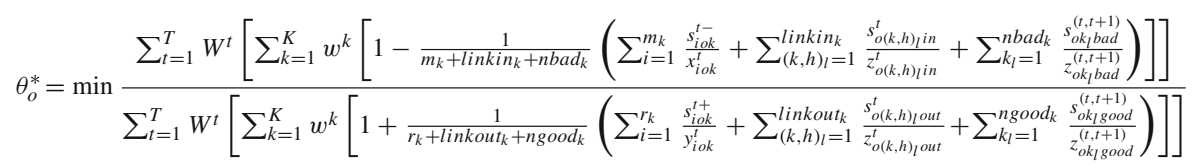

Subject to (1)-(4), where $W^{t}(t=1, \ldots, T)$ is the weight to period $t$ and $w^{k}(k=1, \ldots, K)$ is the weight to Division $k$. These weights satisfy the condition $\sum_{t=1}^{T} W^{t}=1, \sum_{k=1}^{K} w^{k}=1,=W^{t} \geq 0(\forall t), w^{k} \geq 0(\forall k)$. They are supplied exogenously. The input-(output-) oriented model can be defined by dealing with the numerator (denominator) of the above objective function.

Period efficiency is defined by

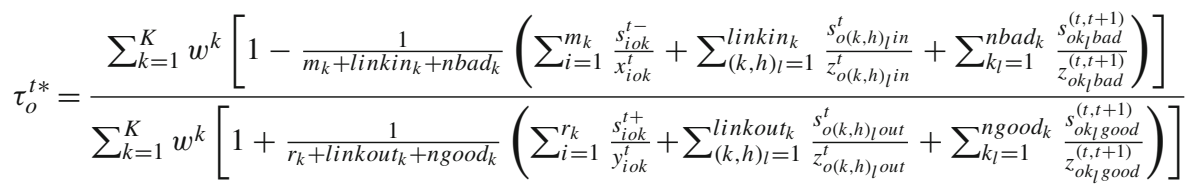

$$
\begin{aligned}
& (t=1, \ldots, T)
\end{aligned}
$$

where variables on the right hand side indicate optimal values for the overall efficiency $\theta_{o}^{*}$. 
Divisional efficiency is defined by

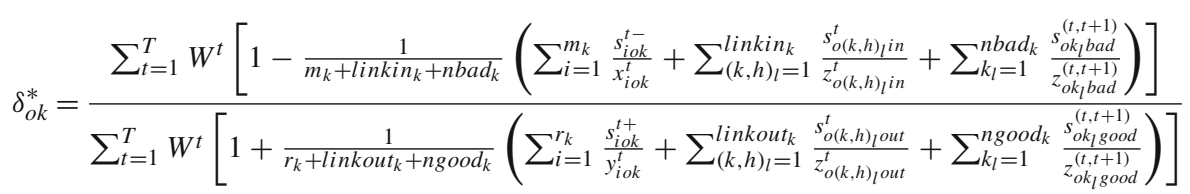

$$
\begin{aligned}
& (k=1, \ldots, K)
\end{aligned}
$$

Finally, period-divisional efficiency is defined by

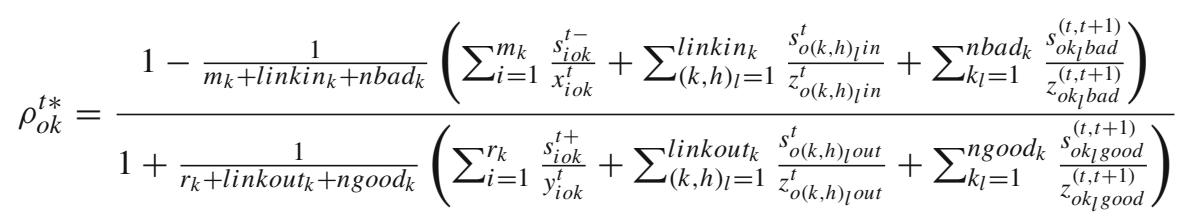

$$
\begin{aligned}
& (k=1, \ldots, K ; t=1, \ldots, T))
\end{aligned}
$$

In the input- (output-) oriented model, the numerator (denominator) of the above formulas is applied [*the above formulaewere adapted from Tone and Tsutsui (2014)].

The model being used in this paper as shown in Fig. 1 considers anOECD country's health system as a DMU. This health system is conceived as having two sub-unitspublic health and medical care. In the model used here, public health and medical care sub-units are assigned equal weights since both are essential components of a health system (Woolf and Aron 2013). The inputs to the public health sub-unit include nonmedical determinants of health outcomes which are beyond the control of medical care systems. These lifestyle inputs contribute significantly to individual health outcomes but their control and regulation is usually a function of the public health department of a country. For example, legislation and health education efforts related to smoking,

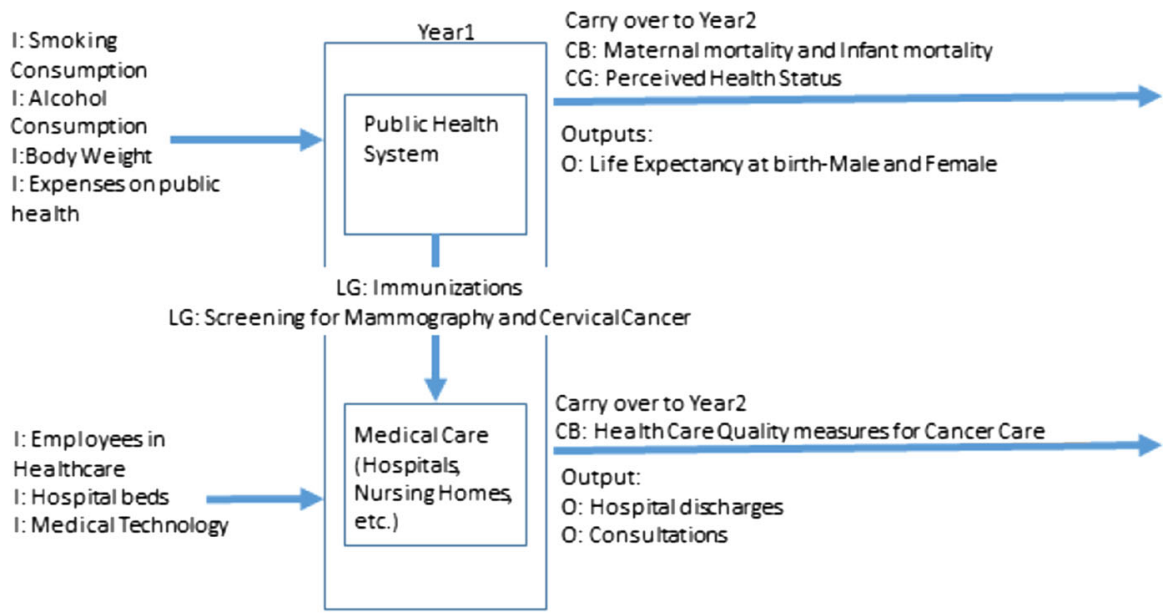

- In Input O=Output LG: Good Link, CG: Good carry over CB: Bad or undesirable corry over

Fig. 1 Dynamic Network DEA model 
alcohol consumption and obesity fall under the purview of the larger public health system of a country. Thus, annual tobacco and alcohol consumption per capita and proportion of the population that is overweight or obese have been included as inputs to the public health system. These inputs have been used in prior studies assessing efficiency of health care systems (Ravangard et al. 2014). Additionally, total of public and private expenditure on public health has also been included as an input to the public health system since monetary resources are an essential input for improving health status of the population (Rivera 2001).

Preventive services such as immunization and screening for chronic disorders have been included as inputs to the medical care system in previous studies (Benneyan et al. 2007). However, these are the inputs which should be maximized rather than minimized to improve health. Additionally, these are usually under the supervision of the public health departments of most nations. Thus these preventive services are included in the model as links from the public health division to the medical care division. These include immunizations i.e. percentage of children under 1 year old who received three doses of the combined Diphtheria-Tetanus-Pertussis vaccine (DTP) in a given year, screening for breast and cervical cancer i.e. number of women aged 5069 who received a bilateral mammography within the past 2 years and the number of women aged 20-69 who received cervical cancer screening in the past 3 years. These have been used as good links to the medical care division as they reduce the disease burden on the medical care division.

Outputs from the public health division include life expectancy at birth for males and females. Carry overs from the public health division include maternal mortality and infant mortality and the perceived health status of the population since these are expected to impact the efficiency of the public health division for a number of years (Almond and Chay 2006; Bazile et al. 2015; Goldstein et al. 1984). Although life expectancy, maternal and infant mortality and perceived health status are outcomes of the entire health system and not just of the public-health division, they have been assigned to the public health division for the purpose of this model since medical care is expected to contribute less to health status, mortality and life expectancy than public health (Bunker et al. 1994; McGinnis et al. 2002). All of these outputs and carry-overs are commonly used measures when computing efficiency of health systems (Afonso and St Aubyn 2006; Mirmirani et al. 2011; Ozcan 2014).

The inputs to the medical care sub-unit include total number of hospital beds in the country, number of persons working in the health care and social work sector in the country and number of Computed Tomography (CT) scanners in the country. These inputs represent capital, labor and technology and are commonly used while assessing efficiency of health care providers.Outputs from the medical care division include number of inpatient discharges and outpatient consults in a year. These are commonly used outputs in assessment of productivity of the medical care system (Ozcan 2014). Carry overs from the medical care division include number of new cancer cases diagnosed. New cancer cases are an undesirable input to the medical care system but their impact lasts much longer than a given year since cancer is a chronic condition that demands medical resources over time. Thus, it has been included as a bad carry-over of the medical care system from one period to the other.

The DNDEA model used in this paper is presented in Fig. 1. 


\subsection{Data source, sample and analysis}

The data used for the purpose of this study was derived from the OECD health data for the years 2000 and 2012. OECD health data is an annual database developed by the OECD Health Policy Unit in Paris. The data were contributed by the member countries and verified by the OECD to insure accuracy and consistency to allow accurate comparisons across healthcare systems. This database provides a rich spectrum of cross-country data for industrialized countries. However, previous analyses of OECD health data note the measurement problems of using aggregate cross-country data, as the various series may not always be consistently coherent across countries. This data set also has a number of missing values (Retzlaff-Roberts et al. 2004). If data element was missing, an adjacent year's data was used as proxy for that particular country. We included data from all 34 OECD countries.

Dynamic Network DEA Analysis was conducted using DEA-Solver-Pro Professional Version 12. A non-oriented constant returns to scale (CRS) version of DNDEA model was used. The non-oriented model allows assessing input, output, and link deficiencies for those inefficient DMUs. The CRS model reflects the fact that output will change by the same proportion as inputs are changed (e.g. a doubling of all inputs will double output) whereasthe alternate variable returns to scale (VRS) model requires an a priori assumption of whether health systems have an increasing or decreasing returns to scale. Such assumptions could not be made due to unavailability of literature and hence, we use the CRS model in this paper.

Based on the DNDEA results, we will assess whether the countries that underwent reform had higher Malmquist scores overall and for each division. We also assess whether overall Malmquist scores for countries that underwent reform were higher for countries with a Beveridge or Bismarck health system. We do not include the other types of health system in this analyses because the sample size for those are small. We restrict ourselves to descriptive statistics since sophisticated analyses will not provide meaningful results given our small sample size.

\subsection{Results}

Descriptive statistics for all variables used in the Dynamic Network DEA model are presented in Table 2.

Efficiency Scores for the public health sub-unit, medical care sub-unit and overall health system for the 34 OECD countries is presented in Table 3 whereas the overall Malmquist scores, frontier change and catch up scores for the OECD countries are presented in Table 4.

In the given sample of 34 OECD countries, 14 countries underwent reform between 2000 and 2012 whereas 20 countries did not. Malmquist scores above 1 indicate improvement over time. Average overall Malmquist score for the countries that underwent reform is 0.98 whereas for countries that did not undergo reform is 0.95 . Although, the average overall Malmquist score for countries that underwent reform is $>1$, it is still higher that countries that did not undergo reform. Average Malmquist score for the public health division for the countries that underwent reform is 1.09 


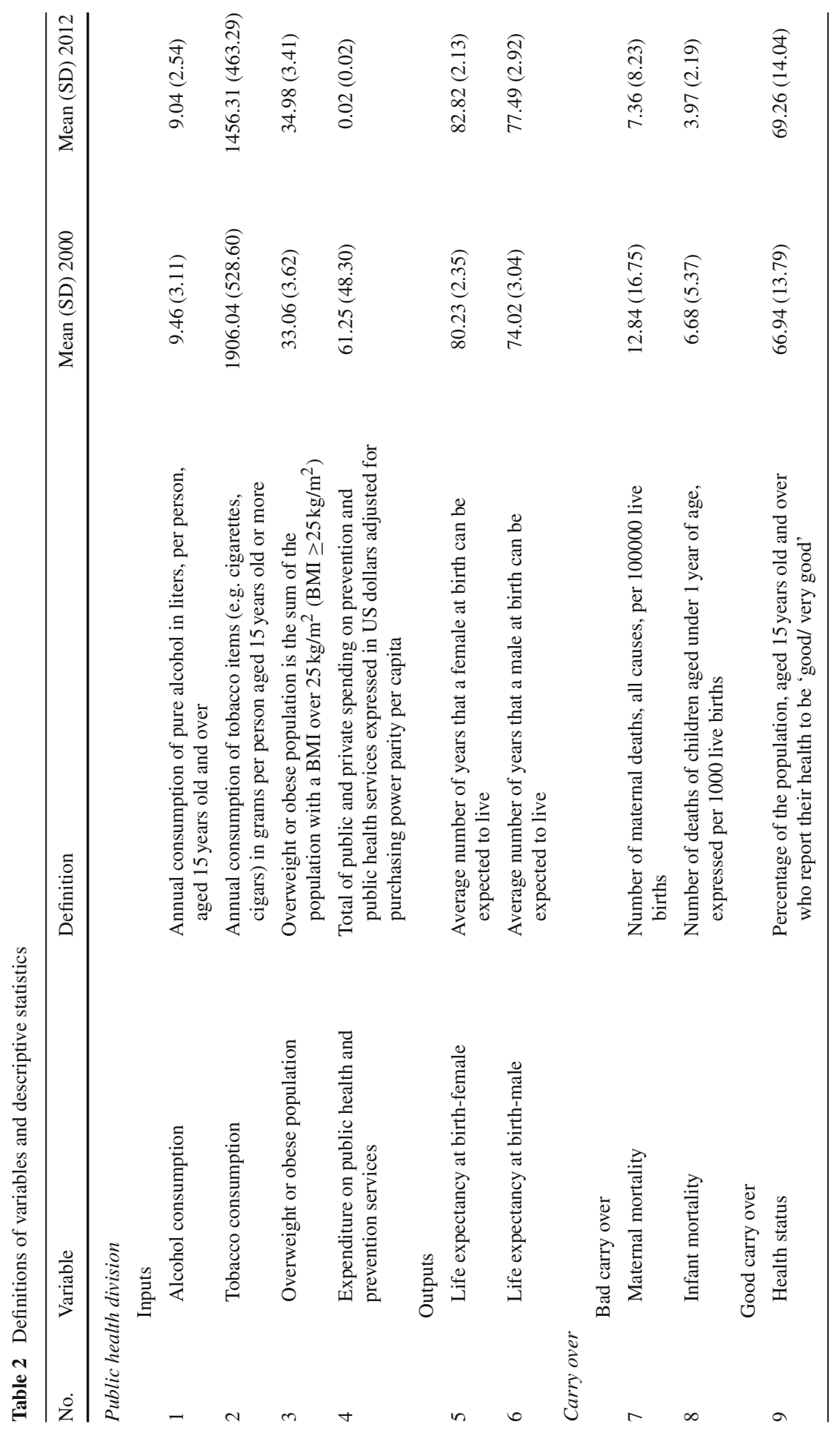




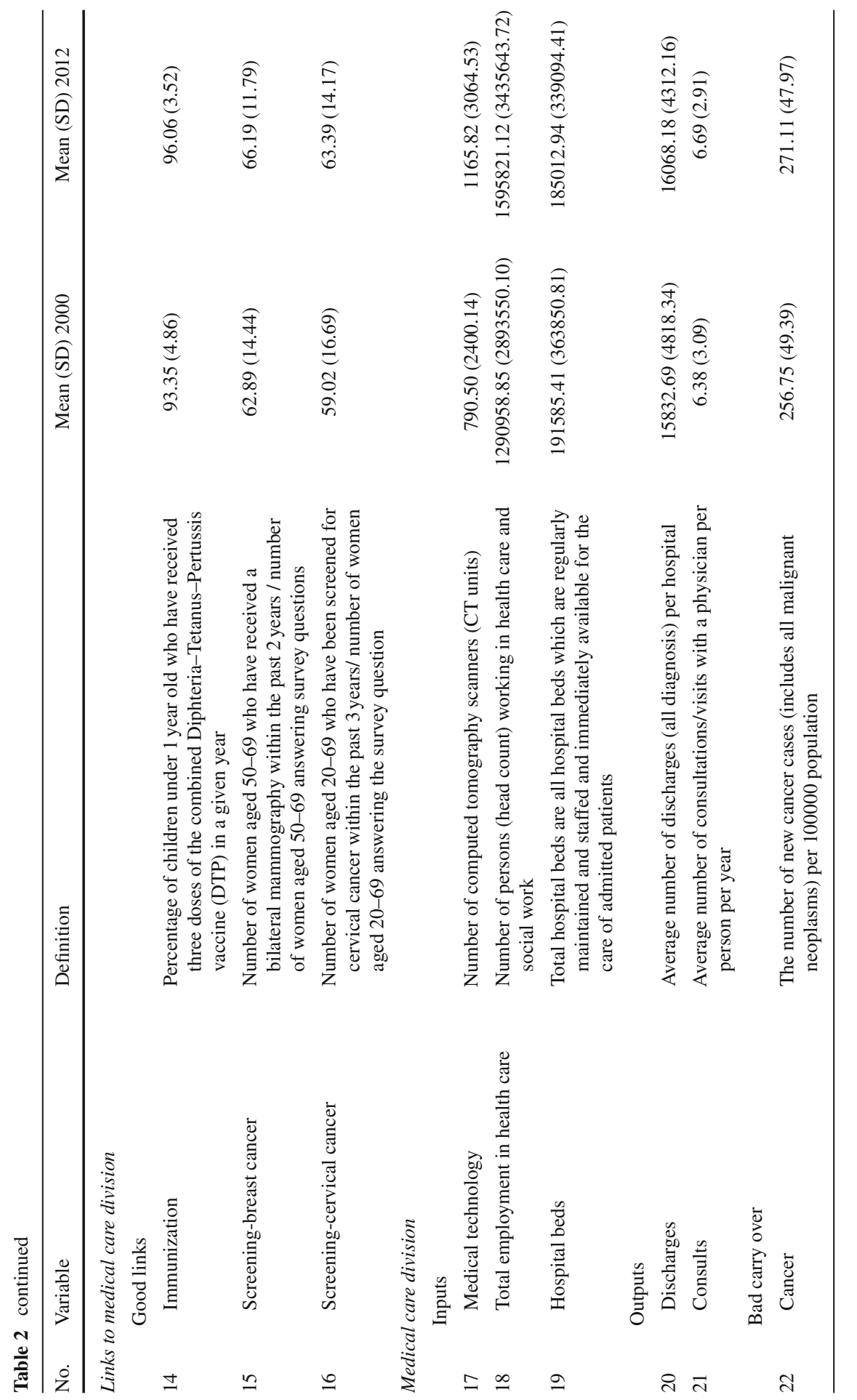


Table 3 Efficiency scores for OECD countries

\begin{tabular}{|c|c|c|c|c|c|c|}
\hline \multirow[t]{2}{*}{ Country } & \multicolumn{2}{|c|}{$\begin{array}{l}\text { Overall efficiency } \\
\text { score }\end{array}$} & \multicolumn{2}{|c|}{$\begin{array}{l}\text { Efficiency score of } \\
\text { Public health division }\end{array}$} & \multicolumn{2}{|c|}{$\begin{array}{l}\text { Efficiency score of } \\
\text { Medical care division }\end{array}$} \\
\hline & 2000 & 2012 & 2000 & 2012 & 2000 & 2012 \\
\hline Australia & 0.5 & 0.6179 & 0.7947 & 0.9811 & 0.4947 & 0.4151 \\
\hline Austria & 1 & 1 & 1 & 1 & 1 & 1 \\
\hline Belgium & 0.6277 & 0.5983 & 0.8617 & 0.7369 & 0.6429 & 0.5796 \\
\hline Canada & 0.6273 & 0.6378 & 1 & 1 & 0.5016 & 0.4868 \\
\hline Chile & 1 & 1 & 1 & 1 & 1 & 1 \\
\hline Czech Rep. & 0.6027 & 0.6679 & 0.6452 & 0.6008 & 0.5623 & 0.7081 \\
\hline Denmark & 0.7794 & 0.6183 & 1 & 1 & 0.8137 & 0.3916 \\
\hline Estonia & 1 & 1 & 1 & 1 & 1 & 1 \\
\hline Finland & 1 & 1 & 1 & 1 & 1 & 1 \\
\hline France & 0.5806 & 0.6199 & 1 & 1 & 0.3716 & 0.3347 \\
\hline Germany & 1 & 1 & 1 & 1 & 1 & 1 \\
\hline Greece & 1 & 1 & 1 & 1 & 1 & 1 \\
\hline Hungary & 0.7648 & 0.7731 & 0.6593 & 0.5704 & 0.8299 & 0.9094 \\
\hline Iceland & 1 & 1 & 1 & 1 & 1 & 1 \\
\hline Ireland & 1 & 0.7561 & 1 & 1 & 1 & 0.7688 \\
\hline Israel & 1 & 1 & 1 & 1 & 1 & 1 \\
\hline Italy & 0.5708 & 0.5428 & 1 & 1 & 0.3751 & 0.375 \\
\hline Japan & 1 & 1 & 1 & 1 & 1 & 1 \\
\hline Korea & 1 & 1 & 1 & 1 & 1 & 1 \\
\hline Luxembourg & 0.8856 & 0.8845 & 0.7716 & 0.7701 & 0.9762 & 0.9469 \\
\hline Mexico & 1 & 1 & 1 & 1 & 1 & 1 \\
\hline Netherlands & 1 & 1 & 1 & 1 & 1 & 1 \\
\hline New Zealand & 1 & 1 & 1 & 1 & 1 & 1 \\
\hline Norway & 0.6966 & 1 & 1 & 1 & 0.583 & 1 \\
\hline Poland & 1 & 1 & 1 & 1 & 1 & 1 \\
\hline Portugal & 1 & 1 & 1 & 1 & 1 & 1 \\
\hline Slovak Rep. & 1 & 1 & 1 & 1 & 1 & 1 \\
\hline Slovenia & 1 & 1 & 1 & 1 & 1 & 1 \\
\hline Spain & 1 & 1 & 1 & 1 & 1 & 1 \\
\hline Sweden & 0.67 & 0.7743 & 1 & 1 & 0.6021 & 0.5487 \\
\hline Switzerland & 1 & 1 & 1 & 1 & 1 & 1 \\
\hline Turkey & 1 & 1 & 1 & 1 & 1 & 1 \\
\hline United Kingdom & 0.4047 & 0.4158 & 0.7482 & 0.6978 & 0.3726 & 0.4352 \\
\hline United States & 0.4152 & 0.4329 & 1 & 1 & 0.2284 & 0.2521 \\
\hline
\end{tabular}

whereas for countries that did not undergo reform is 1.06. Average Malmquist score for the public health division is $>1$ for countries that underwent reform and for those that did not. However, countries that underwent reform had a higher Malmquist score 


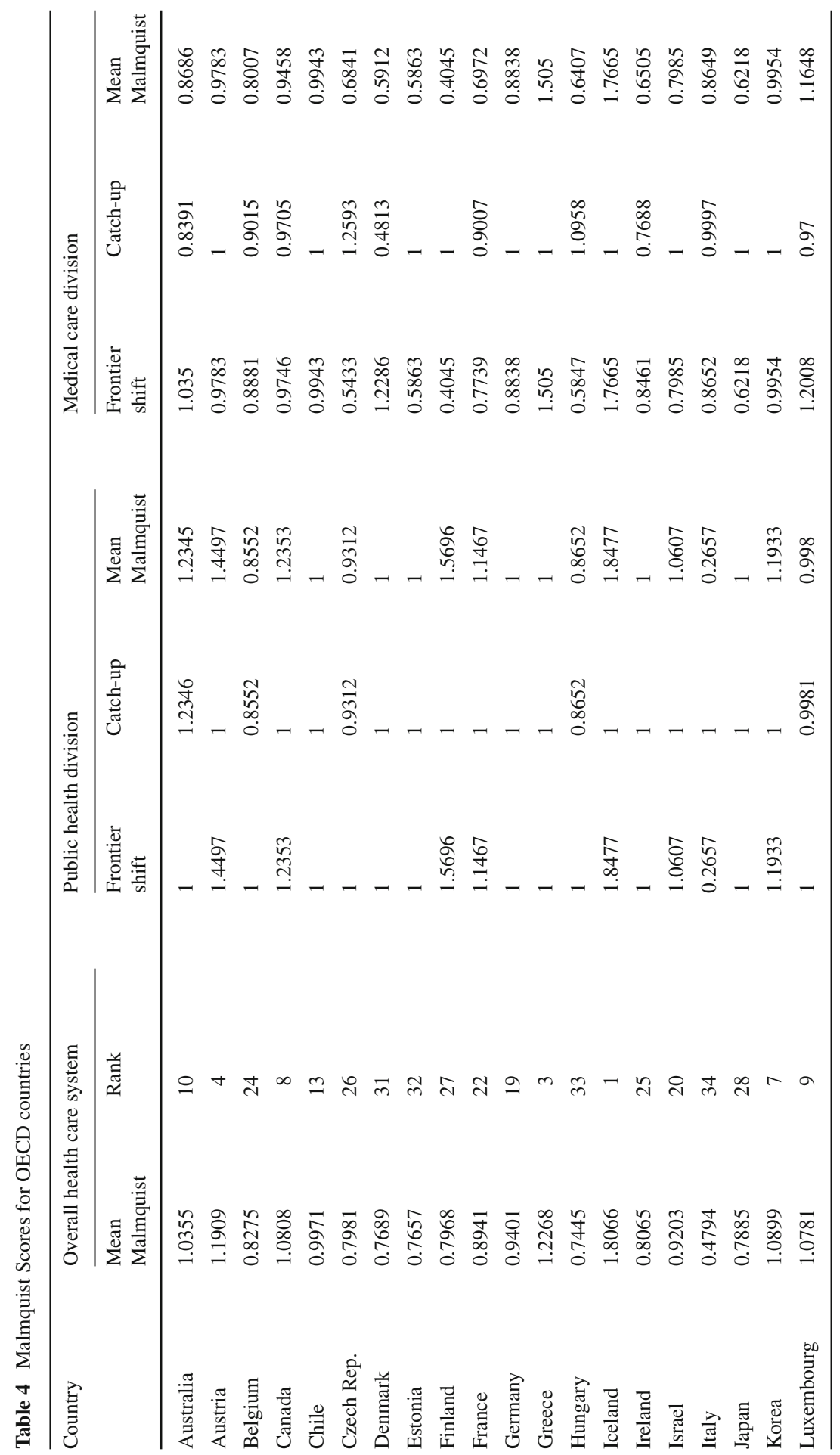




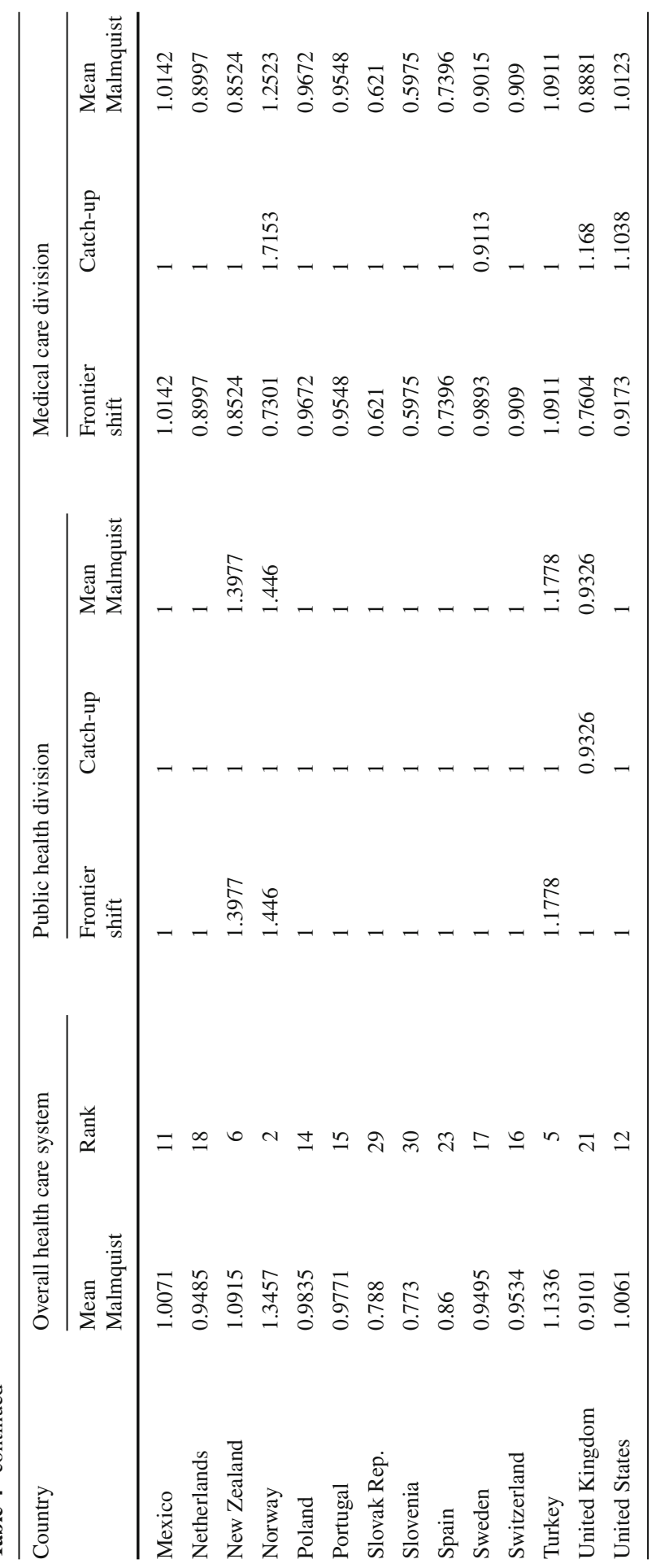


for the public health division. Similarly, average Malmquist score for the medical care division for the countries that underwent reform is 0.89 whereas for countries that did not undergo reform is 0.88 . Average Malmquist score for the medical care division is $>1$ for countries that underwent reform and for those that did not. However, countries that underwent reform had a higher Malmquist score for the medical care division.

Among the countries that underwent reform, overall Malmquist score (1.04 for the 6 countries with Beveridge health system vs. 0.90 for the 6 countries with the Bismarck health system) and Malmquist scores for the public health division (1.10 for the 6 countries with Beveridge health system vs. 1.07 for the 6 countries with the Bismarck health system) and medical care division (1.10 for the 6 countries with Beveridge health system vs. 1.07 for the 6 countries with the Bismarck health system) were higher for countries with the Beveridge health system than the Bismarck health system.

\subsection{Discussion and policy implications}

Results from this study indicate that countries that underwent reform showed more improvement in the efficiency of the overall health system and both divisions as compared to the countries that did not. This was especially true for countries with the Beveridge health system. Further research is needed to understand this link between the type of health system and improved efficiency after reform.

The Malmquist scores show that amongst all countries that underwent reform in the past decade, Austria, Canada, Mexico, Norway, Turkey and United States showed improvement in efficiency of the overall health system over time. It is interesting to note that this improvement in the overall health system efficiency was driven by better improvement in the efficiency of the public health system as compared to the medical care system for four of the six countries. Thus, efficiency of the public health system plays an important role in the efficiency of the overall health system. Improving the efficiency of the public health system should therefore be a priority for nations.

Most countries that underwent reform either improved or retained the efficiency scores for their overall health system between 2000 and 2012. The only exceptions to this was Denmark. This can possibly be explained by the fact that reform in Denmark was passed with a very small political majority and thus, did not enjoy complete political support (Olejaz et al. 2012). A complete analyses of characteristics of reforms and their association with improvement in health system efficiency for all countries is out of the scope of this paper and should be explored in future research.

The Dynamic Network DEA model used in this paper also provides projections for various inputs, outputs and carryovers which can help guide priorities for improving health systems of nations. The average projections (\% difference between actual values and values projected for achieving efficiency) of inputs for all OECD countries that underwent reform compared to those that did not are listed in Table 5. As can be seen from the table, the maximum reduction is needed in the inputs in countries that did not undergo reform. The inputs to the medical care system need to be reduced more than the inputs to the public health system. 
Table 5 Projections of inputs for countries with low efficiency health systems

\begin{tabular}{lll}
\hline Input & $\begin{array}{l}\text { Average \% difference between } \\
\text { actual and projected values } \\
\text { for countries with reform }\end{array}$ & $\begin{array}{l}\text { Average \% difference between } \\
\text { actual and projected values } \\
\text { for countries without reform }\end{array}$ \\
\hline $\begin{array}{l}\text { Public health } \\
\text { Alcohol }\end{array}$ & -2.35 & -4.60 \\
Tobacco & 0 & -8.14 \\
Obesity & 0 & 0 \\
Expenses on public health & -2.96 & -11.73 \\
Medical care & & -25.40 \\
Medical technology & -16.25 & -18.89 \\
Beds & -13.32 & -28.07 \\
Health employment & -19.42 & \\
\hline
\end{tabular}

Health reforms of most nations are geared towards cost containment. The findings of this study suggest that this cost containment should be directed towards the medical care system and not the public health system in order to derive improved health system efficiency after the reform. Reforms of countries which improved the efficiency of their health systems need to be examined in order to embrace the best features of their health care reform.

This paper makes significant contributions to literature by introducing the use of a new model for assessing efficiency of health care systems which allows independent examination of the public health and the medical care system. This use of this model is relatively new in the health care literature and the current paper demonstrates an innovative use of this model. Additionally, this paper contributes to literature on assessment of efficiency of health systems of OECD countries by using a 10 year long panel dataset which covers a period of time characterized by active health reform in a number of OECD countries.

In spite of the significant contributions to literature, this has some limitations. The OECD Health Stats database suffers from missing data which had to be imputed using data from other years for thepurpose of this study. Although imputation is a commonly used technique, it may introduce a minor amount of bias in the findings. Additionally, inputs and outputs of the public health and medical care systems of nations are highly complex constructs. The variables selected to represent these constructs only serve as a proxy to measure them. Although this study employs variables commonly used in previous literature, there are a number of other variables which may be chosen as part of the DEA model. The results from the DEA model may vary based on thevariables selected to represent each construct.

\section{References}

Afonso A, St Aubyn M (2006) Relative efficiency of health provision: A DEA approach with nondiscretionary inputs. ISEG-UTL economics working paper, vol. 33 
Aktan AO, Pala K, Ilhan B (2014) Health-care reform in Turkey: far from perfect. Lancet (London, England) 383(9911):25-26

Allin S, Mossialos E, McKee M, Holland W (2004) Making decisions on public health: a review of eight countries WHO. Retrieved from http://www.euro.who.int/_data/assets/pdf_file/0007/98413/ E84884.pdf

Almond D, Chay KY (2006) The long-run and intergenerational impact of poor infant health: evidence from cohorts born during the Civil Rights Era. 2006. NBER working paper

Andersen PT, Jensen JJ (2010) Healthcare reform in Denmark. Scand J Public Health 38(3):246-252

Bambra C, Beckfield J (2011) Institutional arrangements as candidate explanations for the US mortality disadvantage. Background paper for the NAS/IOM panel on understanding international health differences in high-income countries. The National Academies/Institute of Medicine, Washington. Retrieved from http://scholar.harvard.edu/files/jbeckfield/files/bambra_and_beckfield_2012.pdf

Barros PP (2012) Health policy reform in tough times: the case of portugal. Health Policy 106(1):17-22

Bazile J, Rigodon J, Berman L, Boulanger VM, Maistrellis E, Kausiwa P, Yamin AE (2015) Intergenerational impacts of maternal mortality: qualitative findings from rural Malawi. Reprod Health 12(Suppl 1):S1

Benneyan J, Ceyhan M, Sunnetci A (2007) Data envelopment analysis of national healthcare systems and their relative efficiencies. Paper presented at the the 37th international conference on computers and industrial engineering, pp 251-261

Boutsioli Z (2011) A promising health care reform in greece: the emphasis is on hospitals. Int J Healthc Deliv Reform Initiat (IJHDRI) 3(2):23-27

Bunker JP, Frazier HS, Mosteller F (1994) Improving health: measuring effects of medical care. Milbank Q 72(2):225-258

Byrkjeflot H (2004) The making of a health care state? An analysis of the recent hospital reform in Norway. Paper Presented at the EGOS Colloquum, Lubljana, 1-4 July 2004

Centers for Disease Control and Prevention (1999) Ten great public health achievements-United States, 1900-1999. Morb Mortal Wkly Rep 48(12):241-243

Cutler DM, Miller G (2005) The role of public health improvements in health advances: the twentiethcentury United States. Demography 42(1):1-22

Färe R, Grosskopf S, Norris M, Zhang Z (1994) Productivity growth, technical progress, and efficiency change in industrialized countries. Am Econ Rev 84(1):66-83

Färe R, Grosskopf S (2000) Network DEA. Socio Econ Plan Sci 34:35-49

Fielding J, Tilson H, Richland J (2008) Medical care reform requires public health reform: expanded role for public health agencies in improving health. Partnership for prevention. Retrieved from https:// www.prevent.org/data/files/initiatives/medicalcarereformrequirespublichealthreform.pdf

Foege WH (2004) Redefining public health. J Law Med Ethics 32(Suppl. 4):S23-S26

Gaal P (2011) Health systems in transition: Hungary: health system review. European observatory on health systems and policies. Retrieved from http://www.euro.who.int/_data/assets/pdf_file/0019/155044/ e96034.pdf

Gerlinger T (2010) Health care reform in Germany. Ger Policy Stud 6(1):107-142

Goldstein MS, Siegel JM, Boyer R (1984) Predicting changes in perceived health status. Am J Public Health 74(6):611-614

Gruber J, Sekhon JS (2010) Fundamental health care reform for the United States. Significance 7(3):122127

Häkkinen U, Joumard I (2007) Cross-country analysis of efficiency in OECD health care sectors. Retrieved from http://www.oecd-ilibrary.org/docserver/download/514nrhnfdlzq.pdf?expires $=1448751765 \&$ $\mathrm{id}=\mathrm{id} \&$ accname $=$ guest $\&$ checksum $=$ CDD17A7C01E839B8A3BE04D497AFD1E0

Hollingsworth B, Wildman J (2003) The efficiency of health production: re-estimating the WHO panel data using parametric and non-parametric approaches to provide additional information. Health Econ 12(6):493-504

Ikegami N, Campbell JC (2004) Japan's health care system: containing costs and attempting reform. Health Aff 23(3):26-36

Kacak H, Ozcan YA, Kavuncubasi S (2014) A new examination of hospital performance after healthcare reform in turkey: sensitivity and quality comparisons. Int J Public Policy 10(4):178-194

Kawaguchi H, Tone K, Tsutsui M (2014) Estimation of the efficiency of japanese hospitals using a dynamic and network data envelopment analysis model. Health Care Manag Sci 17(2):101-112

Klopp GA (1985) The analysis of the efficiency of production system with multiple inputs and outputs. $\mathrm{PhD}$ dissertation, University of Illinois at Chicago, Industrial and System Engineering College 
Kulesher R, Forrestal E (2014) International models of health systems financing. J Hosp Adm 3:127-139

Laurell AC (2007) Health system reform in mexico: a critical review. Int J Health Ser Plan Adm Eval 37(3):515-535

Magnussen J, Vrangbæk K, Saltman R (2009) Nordic health care systems: recent reforms and current policy challenges. McGraw-Hill Education, UK

McGinnis JM, Williams-Russo P, Knickman JR (2002) The case for more active policy attention to health promotion. Health Aff 21(2):78-93

Mirmirani S, Li H, Ilacqua JA (2011) Health care efficiency in transition economies: an application of data envelopment analysis. Int Bus Econ Res J (IBER) 7(2):47-56

Mohan R, Mirmirani S (2007) An assessment of OECD health care system using panel data analysis. Southwest Bus Econ J 16:21-25

Narcı HÖ, Ozcan YA, Şahin İ, Tarcan M, Narc1 M (2015) An examination of competition and efficiency for hospital industry in Turkey. Health Care Manag Sci 18(4):407-418

National Health and Hospitals Reform Commission (Australia) (2009) A healthier future for all Australians: final report June 2009. Department of Health and Ageing. Retrieved from http://www.health.gov. au/internet/nhhrc/publishing.nsf/content/1AFDEAF1FB76A1D8CA257600000B5BE2/File/Final_ Report_of_the\%20nhhrc_June_2009.pdf

Nolte E, Knai C, Hofmarcher M, Conklin A, Erler A, Elissen A, Vrijhoef HJ (2012) Overcoming fragmentation in health care: chronic care in Austria, Germany and the Netherlands. Health Econ Policy Law $7(01): 125-146$

Office of the Government of the Czech Republic (2013) National reform programme of the Czech Republic 2013. Retrieved from http://www.vlada.cz/assets/evropske-zalezitosti/dokumenty/ NPR-2013-v-PDF-_AJ_.pdf

Olejaz M, Juul A, Rudkjøbing A, Birk HO, Krasnik A (2012) Denmark: health system review: health systems in transition. World Health Organization, Copenhagen. Retrieved from http://www.euro.who. int/_data/assets/pdf_file/0004/160519/e96442.pdf

Ozcan YA (2014) Health care benchmarking and performance evaluation an assessment using data envelopment analysis (DEA), 2nd edn. Springer, Newton

Ravangard R, Hatam N, Teimourizad A, Jafari A (2014) Factors affecting the technical efficiency of health systems: a case study of economic cooperation organization (ECO) countries (2004-2010). Int J Health Policy Manag 3(2):63

Reid TR (2010) The healing of America: a global quest for better, cheaper, and fairer health care. Penguin, New York, NY

Retzlaff-Roberts D, Chang CF, Rubin RM (2004) Technical efficiency in the use of health care resources: a comparison of OECD countries. Health Policy 69(1):55-72

Rivera B (2001) The effects of public health spending on self-assessed health status: an ordered probit model. Appl Econ 33(10):1313-1319

Schafer W, Kroneman M, Boerma W, van den Berg M, Westert G, Deville W, van Ginneken E (2010) The Netherlands: health system review. Health Syst Trans 12(1):1-228

Simms C (2010) Health reform in Canada. Int J Clin Pract 64(4):426-428

Szalay T, Pazitny P, Szalayova A, Frisova S, Morvay K, Petrovic M, van Ginneken E (2011) Slovakia health system review. Health Syst Trans 13(2):1-174

Thomson S, Võrk A, Habicht T, Rooväli L, Evetovits T, Habicht J (2010) Responding to the challenge of financial sustainability in Estonia's health system. World Health Organization Regional Office for Europe, Copenhagen

Tone K, Tsutsui M (2009) Network DEA: a slacks-based measure approach. Eur J Oper Res 197(1):243-252

Tone K, Tsutsui M (2014) Dynamic DEA with network structure: a slacks-based measure approach. Omega 42(1):124-131

Tussing AD, Wren MA (2006) How Ireland cares: the case for health care reform. New Island, Dublin

Unger J, De Paepe P, Cantuarias GS, Herrera OA (2008) Chile's neoliberal health reform: an assessment and a critique. PLoS Med 5(4):e79

Woolf SH, Aron L (2013) US health in international perspective: shorter lives, poorer health. The National Academies/Institute of Medicine, Washington. Retrieved from https://obssr.od.nih.gov/pdf/ IOM\%20Report.pdf

Yaya S, Danhoundo G (2015) Introduction: special issue on innovations in health care system reform in OECD countries. Innov J 20(1):1 